\title{
Mechanical Performance Test of Rubber-Powder Modified Concrete
}

\author{
Yan Cong ZHANG ${ }^{1, \mathrm{a}}$, Ling Ling $\mathrm{GAO}^{2, \mathrm{~b}}$ \\ ${ }^{1}$ Key Laboratory of Highway Construction \& Maintenance in Loess Region, Shanxi Research Transportation Institute, Taiyuan 030006, \\ China \\ ${ }^{2}$ Shanxi Conservancy Technical College, Yuncheng, 044004, China
}

\begin{abstract}
A number of rubber cement concrete specimens that rubber powder dosage different were obtained using same cement, water and fine aggregates, by adjusting the dosage of rubber powder. Then it was used to research the influence of rubber powder dosage on performance of cement concrete by measuring its liquidity, strength and toughness. The results show that: when water-cement ratio was equal and rubber powder replacing the same volume sand, the fluidity of cement concrete almost linear increased with rubber powder dosage increasing. With dosage of rubber powder increasing, compressive strength and flexural strength reduced, but toughness linear growth trend when dosage of rubber powder less $30 \%$.
\end{abstract}

\section{Introduction}

Waste rubber powder was a renewable resource. It was widely used in road construction technology at home and abroad, not only improved road performance but also significantly reduced noise, prolong its life [1]- [3].

Therefore, scholars in domestic and foreign do more research on rubber powder cement concrete or concrete [4]-[7]. Most of researchers replaced rubber particles with coarse aggregate, and then researched the properties of rubber concrete [5]-[18]. So, study on rubber powder cement concrete that replaced rubber powder with fine aggregate was less. This paper obtained a number of rubber cement dosage specimens that rubber powder dosage different to study effect of rubber powder ash on cement concrete fluidity, strength and toughness.

\section{Raw Material}

\subsection{Cement}

Lafarge P.O42.5 cement made in Beijing was used in the testing. The physical and mechanical properties of cement were shown in Table 1.

Table 1 Performance index of cement

\begin{tabular}{ccccccc}
\hline & \multicolumn{2}{c}{ Setting time/min } & \multicolumn{2}{c}{$\begin{array}{c}\text { Compressive } \\
\text { strength } / \mathrm{MPa}\end{array}$} & \multicolumn{2}{c}{ Flexural strength/MPa } \\
\cline { 2 - 6 } $\begin{array}{c}\text { Fineness } \\
/\left(\mathrm{m}^{2} / \mathrm{kg}\right)\end{array}$ & $\begin{array}{c}\text { Initial } \\
\text { setting }\end{array}$ & Final setting & $3 \mathrm{~d}$ & $28 \mathrm{~d}$ & $3 \mathrm{~d}$ & $28 \mathrm{~d}$ \\
\hline 350 & 180 & 275 & 5.6 & 49.8 & 6.1 & 8.9 \\
\hline
\end{tabular}

\subsection{Fine Aggregate}

Fine aggregate was river sand choosing from Qinhuangdao. It belonged to zone II. The fineness modulus was 2.8 , and apparent density was $2.6 \mathrm{~g} / \mathrm{cm}^{3}$. The fineness modulus of ultra-fine sand was 0.8 . The grading of ultra-fine sand and ordinary sand was fine.

\subsection{Coarse Aggregate}

Coarse aggregate was choosed from Beijing. The apparent density was $2.7 \mathrm{~g} / \mathrm{cm}^{3}$. 


\subsection{Rubber Powder}

80 mesh rubber powder was used in this testing. The density was $1.2 \mathrm{~g} / \mathrm{cm}^{3}$ and its bulk density was $0.3 \mathrm{~g} / \mathrm{cm}^{3}$.

\section{Testing Methods}

Single factor method was used in the testing to determine the effect of rubber powder dosage on liquidity, compressive strength, flexible strength and toughness by adjusting the dosage of rubber powder. Meanwhile the other raw material was same.

Workability, strength test referenced to the guide that "cement and concrete testing procedures for highway" (JTG E30-2005). Rubber concrete toughness was determined by flexural load-deformation curve and trabecular specimen testing. Specimen size and loading position was equal to flexural strength testing. The curve that flexural load-deformation of rubber concrete trabecular was measured using MTS-810 at the rate of $0.5 \mathrm{~mm} / \mathrm{min}$.

When workability was measured, select three kinds of rubber powder dosage replace sand with equal volume rates were as follows: $10 \%, 20 \%$, and $30 \%$. The basis amount of cement was $600 \mathrm{~g}$, sand was $1500 \mathrm{~g}$, aggregate was $3100 \mathrm{~g}$, and water-cement ratio was 0.5 .
When strength was measured, select ten kinds of rubber powder dosage replace sand with equal volume rates were as follows: $1 \%, 3 \%, 5 \%, 7 \%, 9 \%, 10 \%, 15 \%$, $20 \%, 25 \%$ and $30 \%$. The basis amount of cement was $600 \mathrm{~g}$, aggregate was $3100 \mathrm{~g}$, sand was $1500 \mathrm{~g}$, and water-cement ratio was 0.5 .

When toughness was measured, select three kinds of rubber powder dosage replace sand with equal volume rates were as follows: $10 \%, 20 \%$ and $30 \%$. The basis amount of cement was $600 \mathrm{~g}$, sand was $1500 \mathrm{~g}$, and water-cement ratio was 0.5 . The basis specimen was marked 3-0, and the other was 3-1, 3.2, and 3-3.

\section{Testing Results and Analysis}

By test method described above, the influence of rubber powder dosage on performance of cement concrete by measuring its liquidity, strength and toughness was shown as follows.

\subsection{Effect of rubber powder dosage on workability}

The workability and liquidity testing results of cement concrete mixed with different rubber powder dosage was shown in Figure 1 and Figure 2.

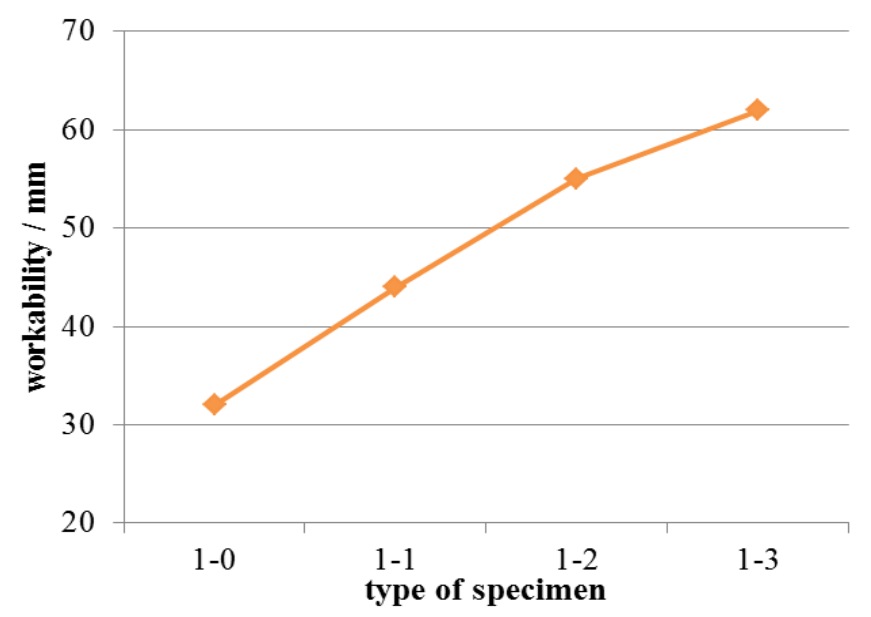

Figure 1 Rubber powder dosage and workability

As can be seen from the Figures, when cement ratio was same, workability of the cement concrete linearly increased with rubber powder dosage increased. Crumb replaced by fine sand dosage volume ratio, due to less dense rubber powder was loose state, resulting in lesser quality rubber powder instead of the larger mass of fine sand, in the water-cement ratio under the same conditions, with the significantly crumb content increased, the corresponding amount of water absorption of the cement concrete has been reduced, an increase in free water. While the reduction of fine sand, causing concrete cement particles and aggregate particles sliding frictional resistance reduction. Therefore, the workability of the cement concrete increased with increasing of rubber powder dosage. 


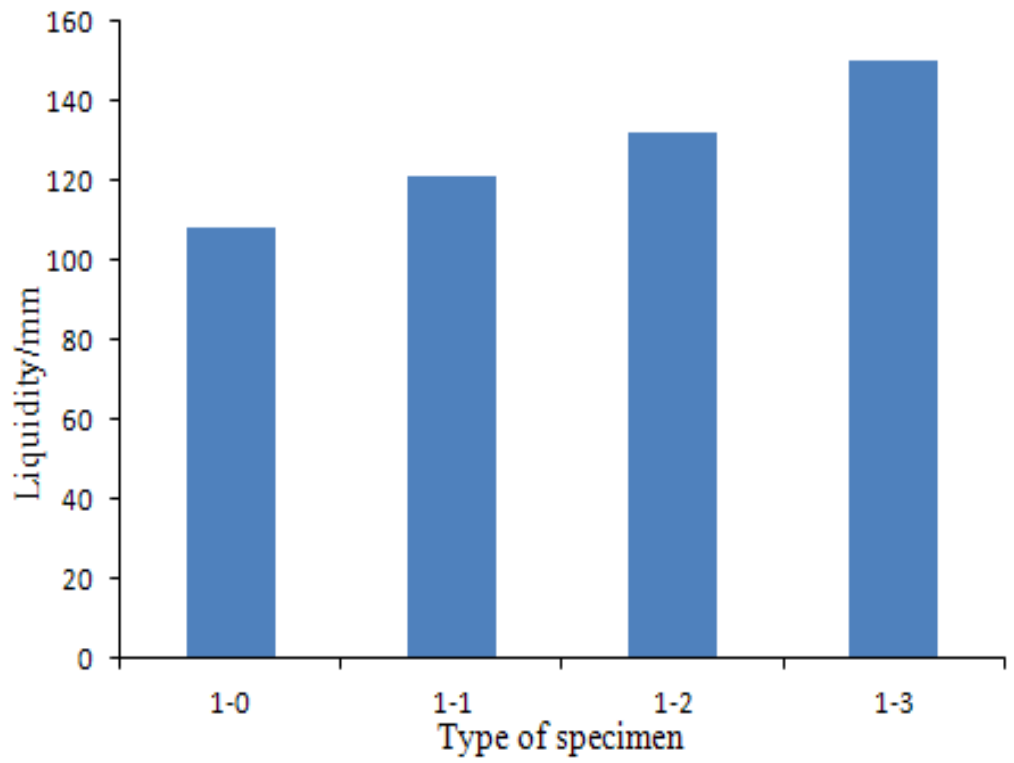

Figure 2 Rubber powder dosage and liquidity

\subsection{Effect of rubber powder dosage on cement concrete strength}

The compress strength and flexible strength testing results of cement concrete mixed with different rubber powder dosage was shown in Figure 3.

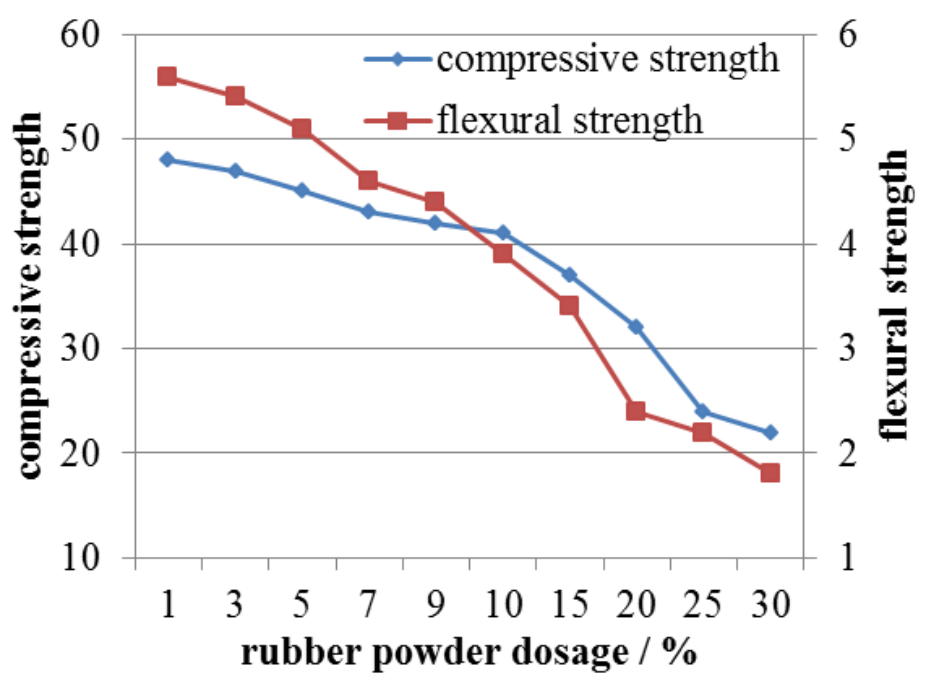

Figure 3 Rubber powder dosage and strength

It can be get following conclusions from Figure 2: (1) With the dosage of rubber powder increasing, 28 days compressive strength and flexural strength of rubber powder significantly decreased. Compress strength decreased by $43 \%$, while flexural strength dropped $32 \%$. The decreasing amplitude of flexural strength less than compress strength. (2) The ratio of flexural strength and compress strength increases gradually with rubber powder dosage increasing.

\subsection{Effect of rubber powder dosage on toughness}

The toughness testing results of cement concrete mixed with different rubber powder dosage was shown in
Figure 4.

Toughness increased with rubber powder dosage increasing. It was relevant with that rubber powder was low modulus and elastic material, the elastic modulus of the cement concrete material greatly concerned. Incorporated into rubber powder in the cement concrete, the deformation small capacity concrete material was rubber powder instead of the deformation capacity. So, when load was equal, the greater dosage of the rubber powder, the greater the deformation capacity of the material. Stress-strain curves belonged to specimen that rubber powder dosage was different was close to a straight line. Rubber powder improved the elasticity of cement concrete material, even larger strain, the material remains at elastic state. 


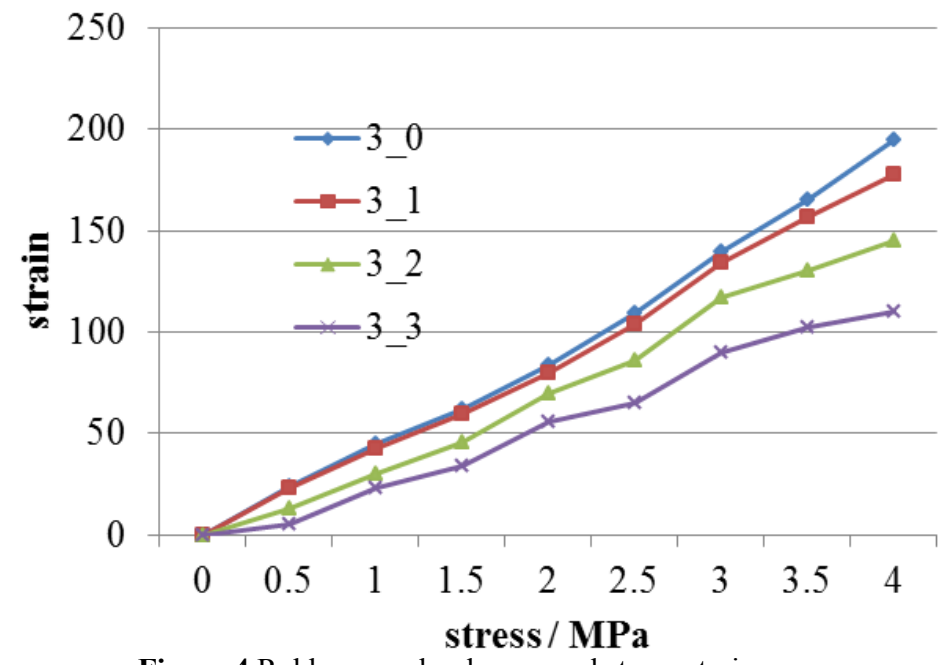

Figure 4 Rubber powder dosage and stress-strain curve

\section{Conclusion}

A number of rubber cement concrete specimens that rubber powder dosage different were obtained using same cement, water and fine aggregates, by adjusting the dosage of rubber powder. Then it was used to research the influence of rubber powder dosage on performance of cement concrete by measuring its liquidity, strength and toughness.

The result shows that: 1 , When water-cement ratio was equal, and rubber powder replaced sand by equivalent volume amount, the workability of cement concrete linearly increased with rubber powder dosage increasing. 2, Compress strength and flexural strength of cement concrete gradually reduced with dosage of rubber powder increased. When dosage was greater than $10 \%$, strength decreased sharply with dosage increasing. Meanwhile, the ratio of flexible strength and compress strength increased. 3, When water-cement ratio was equal, rubber powder replaced sand by equivalent volume amount, and rubber powder dosage was less than $30 \%$, toughness of cement concrete increased with dosage of rubber powder increasing. 4, Rubber powder improved brittleness of cement concrete. It maintained concrete keeping flexible at a large strain range.

\section{Acknowledgements}

This research was supported by Shanxi natural science foundation project (2015021115), and Shanxi province communications department Science and Technology Project (2015-1-26, 2017-1-17).

\section{References}

1. SHEN Junmin, LI Yinbang. The damage survey and evaluation of old cement concrete pavement under heavy-load [J]. Shanxi science \& technology of communication, 2012,1:15-17.

2. F. Hemandez - Olivares, G. Barluenga. Fire performance of recycled rubber-filled high strength concrete $[\mathrm{J}]$. Cement and Concrete Research, 2004, 34: 109-117.

3. Li Lijuan, Chen Zhize, Xie Weifeng. Experimental study of performance of high $\mathrm{s}$ trength concrete modified by recycled rubber powder $[\mathrm{J}]$. Concrete. 2007 (05): 60-63.

4. Jeong Jin-Hoon, Dan G, Zollinger $P$ E. Finite-element modeling and calibration of temperature prediction of hydrating Portland cement concrete pavements [J]. Journal of Materials in Civil Engineering, ASCE, 2006, 18(3): 317-324.

5. William G. D, Joe P. M. Experimental Verification of Rigid Pavement Joint Load Transfer Modeling with Ever FE [J]. Transportation Research Record: Journal of the Transportation Research Board.2007, 1684/1999: 81-89.

6. HU Xinmin. Effects of transition layer on cement concrete pavement slab structure [J]. Journal of Chang'an University (Natural Science Edition).2010, 30 (3):37-40.

7. Zhang Yan-Cong, Gao Ling-Ling. Influence of rubber powder dosage on performance of cement mortar[C]. 3th international conference on civil engineer, architecture and building materials, Jinan, 2013.

8. Jeong Jin-Hoon, Dan G, Zollinger $P$ E. Finite-element modeling and calibration of temperature prediction of hydrating Portland cement concrete pavements [J]. Journal of Materials in Civil Engineering, ASCE, 2006, 18(3): 317-324.

9. Ioannides A M, Alexander D R, Hammons M I, et al. Application of artificial neural networks to concrete pavement joint evaluation[R].Washington D C:Transportation Research Board,1996:54-64.

10. Jiang Yingjun, Dai Jingliang. Contact stresses at interfaces between dowels and surrounding concrete [J]. China Journal of Highway and Transport, 2007, 20(2): 29-34.(in Chinese)

11. ASTM Committee. Standard Test Method for Airport Pavement Condition Index Surveys[S]. ASTM Committee, 2004.7 
12. AASHTO. Pavement Management Guide: Executive Summary Report [S]. America Association of State Highway and Transportation Officials, 2001

13. Tournon, G. Segregation of Non-cohereents Mixtures and Concretes [J]. Rilem Bulletin, 1995, 24:15-31.

14. Menkhoff, H. Density Measurement with Radioactive Isotope [J]. Der Bauingenieur, 1958, $12: 465$.

15. William G. D, Joe P. M. Experimental Verification of Rigid Pavement Joint Load Transfer Modeling with Ever FE [J]. Transportation Research Record: Journal of the Transportation Research Board.2007, 1684/1999: 81-89.

16. ZHANG Ruizhuo, LING Tianqing, YUAN Ming.
Influence of Asphalt Semi-rigid Base Modules on Pavement Structural Stress [J]. Journal of Chongqing Jiaotong University (Nature Science). 2011, 30 (4):755-758. (in Chinese)

17. YAO Jialiang, HU Keyi, YUAN Jianbo. Mechanical Performance of Interface between Cement Concrete Pavement and Lean Concrete Base Treated with Different Bond-breaking Layers [J]. Journal of Highway and Transportation Research and Development. 2012, 29 (2):7-12.

18. HU Xinmin. Effects of transition layer on cement concrete pavement slab structure [J]. Journal of Chang'an University (Natural Science Edition .2010, 30 (3):37-40. 